\title{
Anthocyanins inhibit high-glucose-induced cholesterol accumulation and inflammation by activating LXR $\alpha$ pathway in HK-2 cells
}

This article was published in the following Dove Press journal:

Drug Design, Development and Therapy

4 September 2015

Number of times this article has been viewed

\author{
Chunyang $\mathrm{Du}^{1,2, *}$ \\ Yonghong Shi, ${ }^{1,2, *}$ \\ Yunzhuo Ren ${ }^{1,2}$ \\ Haijiang $W_{u^{1,2}}$ \\ Fang Yao ${ }^{1,2}$ \\ Jinying Wei ${ }^{1,2}$ \\ Ming $\mathrm{Wu}^{1,2}$ \\ Yanjuan Hou ${ }^{1,2}$ \\ Huijun Duan ${ }^{1,2}$ \\ 'Department of Pathology, Hebei \\ Medical University, Shijiazhuang, \\ People's Republic of China; ${ }^{2} \mathrm{Hebei}$ \\ Key Laboratory of Kidney Diseases, \\ Shijiazhuang, People's Republic \\ of China \\ *These authors contributed equally \\ to this work
}

\begin{abstract}
The dysregulation of cholesterol metabolism and inflammation plays a significant role in the progression of diabetic nephropathy (DN). Anthocyanins are polyphenols widely distributed in food and exert various biological effects including antioxidative, anti-inflammatory, and antihyperlipidemic effects. However, it remains unclear whether anthocyanins are associated with DN, and the mechanisms involved in the reciprocal regulation of inflammation and cholesterol efflux are yet to be elucidated. In this study, we evaluated the regulation of cholesterol metabolism and the antiinflammatory effects exerted by anthocyanins (cyanidin-3-O- $\beta$-glucoside chloride $[\mathrm{C} 3 \mathrm{G}]$ or cyanidin chloride [Cy]) and investigated the underlying molecular mechanism of action using high-glucose (HG)-stimulated HK-2 cells. We found that anthocyanins enhanced cholesterol efflux and ABCA1 expression markedly in HK-2 cells. In addition, they increased peroxisome proliferator-activated receptor alpha (PPAR $\alpha)$ and liver X receptor alpha (LXR $\alpha)$ expression and decreased the HG-induced expression of the proinflammatory cytokines intercellular adhesion molecule-1 (ICAM1), monocyte chemoattractant protein-1 (MCP1), and transforming growth factor- $\beta 1$ (TGF $\beta 1$ ), as well as NFKB activation. Incubation with the PPAR $\alpha$-specific inhibitor GW6471 and LXR $\alpha$ shRNA attenuated the anthocyanin-mediated promotion of ABCA1 expression and cholesterol efflux, suggesting that anthocyanins activated PPAR $\alpha$-LXR $\alpha$-ABCA1-dependent cholesterol efflux in HK-2 cells. Moreover, the knockout of LXR $\alpha$ abrogated the anti-inflammatory effect of anthocyanins, whereas the PPAR $\alpha$ antagonist GW6471 does not have this effect. Further investigations revealed that LXR $\alpha$ might interfere with anthocyanin-induced decreased ICAM1, MCP1, and TGF $\beta 1$ expression by reducing the nuclear translocation of NFKB. Collectively, these findings suggest that blocking cholesterol deposition and inhibiting the LXR $\alpha$ pathway-induced inflammatory response might be one of the main mechanisms by which anthocyanins exert their protective effects in DN.
\end{abstract}

Keywords: 3 -O- $\beta$-glucoside chloride, cyanidin chloride, diabetic nephropathy, inflammation, liver $\mathrm{X}$ receptor alpha

\section{Introduction}

Diabetes mellitus (DM), which is characterized by long-term hyperglycemia and various diabetes-related complications, is currently a major worldwide epidemic. Of all the important and serious complications, diabetic nephropathy (DN) has become the leading cause of endstage renal disease, and contributes profoundly to patient morbidity and mortality. ${ }^{1}$ Although hyperglycemia and hypertension play key roles in the pathogenesis of DN, potential additional risk factors and the underlying mechanisms behind these effects remain unclear. Moreover, current therapies, including strict glycemic control, intensive insulin treatment, and reduction of hypertension, delay the progression of DN, but do not sufficiently prevent progression to end-stage renal disease. ${ }^{2}$ Therefore, clarifying novel pathogenic mechanisms and exploring additional effective therapeutic strategies is needed urgently.
Correspondence: Huijun Duan Department of Pathology, Hebei Medical University, 36I East Zhongshan Road, Shijiazhuang, Hebei 050017 ,

People's Republic of China

Fax +863 II 86266942

Email duanhj999@163.com 
Hyperglycemia is a primary risk factor for DN, and sustained hyperglycemia promotes lipid accumulation and inflammatory infiltration in the kidneys of patients with type 2 DM. Recently, the intrarenal accumulation of lipids and proinflammatory cytokines was observed in diabetic humans and experimental animal models. ${ }^{3-5}$ Lipotoxicity and inflammation might play an important role in the pathogenesis of DN. Accumulating evidence has suggested that monocyte chemoattractant protein-1 (MCP1), ${ }^{6}$ transforming growth factor- $\beta 1$ (TGF $\beta 1),{ }^{7,8}$ and intercellular adhesion molecule-1 (ICAM1) ${ }^{9}$ are important proinflammatory cytokines involved in the development of DN. In addition, activated nuclear factor- $\mathrm{KB}(\mathrm{NF} \kappa \mathrm{B})$ translocates from the cytoplasm to the nucleus to trigger the expression of its target genes including $M C P 1, I C A M 1$, and $T G F \beta 1$ to induce persistent and enhanced inflammation, which leads to glomerulosclerosis and tubulointerstitial fibrosis. ${ }^{10-13}$ Dysregulated cholesterol metabolism has also been linked to lipid accumulation and inflammation in diabetes. Ruan et $\mathrm{al}^{14}$ showed that interleukin $1 \beta$ (IL-1 $1 \beta$ ) promotes intracellular lipid accumulation in mesangial cells by inhibiting cholesterol efflux. In addition, cholesterol accumulation and ABCA1 downregulation in podocytes plays a pathogenic role in $\mathrm{DN} .{ }^{15}$ ABCA1, a member of the ATP-binding cassette transporter family, facilitates the efflux of cellular cholesterol to extracellular apoA1 or high-density lipoprotein (HDL). ABCA1 expression was reduced in the kidneys of diabetic NOD mice, which was accompanied by increased levels of renal cholesterol. ${ }^{16}$ Acute renal tubular injury can also trigger the downregulation of ABCA1 and cholesterol accumulation. ${ }^{17}$

Numerous studies reveal that peroxisome proliferatoractivated receptor alpha (PPAR $\alpha)$ and liver $\mathrm{X}$ receptor alpha (LXR $\alpha)$, which are upstream of ABCA1, activate a transcriptional cascade to modulate the expression of ABCA1 and cholesterol efflux. ${ }^{18,19}$ High-glucose (HG) was sufficient to downregulate PPAR $\alpha$ and LXR $\alpha$ expression, which was associated with severe dyslipidemia and inflammation in diabetic kidneys. ${ }^{3,20}$ The increase in PPAR $\alpha$ expression reduces triglycerides, total cholesterol, and low-density lipoprotein (LDL) levels markedly, and elevates high-density lipoprotein (HDL) levels. PPAR $\alpha$ deficiency accelerates dyslipidemia in animal models of DN. ${ }^{21}$ A study by Johnston and Waxman ${ }^{22}$ demonstrated that PPAR $\alpha$ could increase the expression of LXR $\alpha$ in macrophages and thereby promote the expression of ABCA1, which subsequently mediates cholesterol efflux to apoA1. In addition to their important role in regulating lipid metabolism, PPAR $\alpha$ and $\mathrm{LXR} \alpha$ exhibit anti-inflammatory effects in many inflammatory and metabolic diseases. Recent studies found that the PPAR $\alpha$ activator fenofibrate ameliorates inflammation by inhibiting NFKB activity and

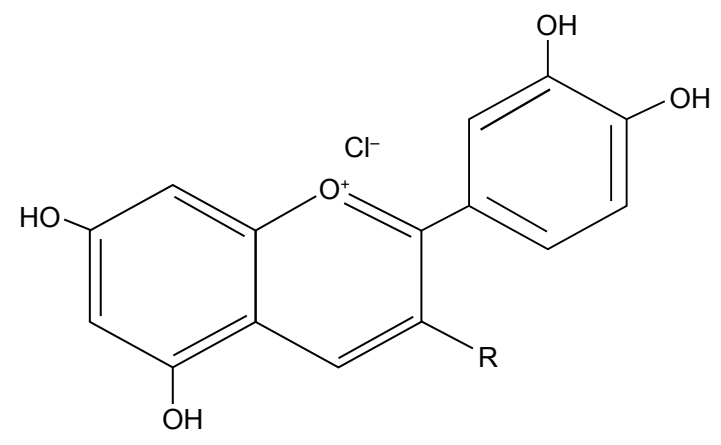

$\mathrm{R}=-\mathrm{O}-\beta-\mathrm{D}-$ glucose; cyanidin-3-glucoside chloride (C3G) $\mathrm{R}=\mathrm{OH}$; cyanidin chloride $(\mathrm{Cy})$

Figure I Chemical structure of cyanidin 3-glucoside chloride (C3G) and cyanidin chloride (Cy).

suppressing the production of the proinflammatory cytokines ICAM1, TGF $\beta 1$, and MCP1..$^{23,24}$ The activation of LXR $\alpha$ also inhibits the production of the proinflammatory cytokines MCP $1,{ }^{25}$ ICAM $1,{ }^{26}$ and TGF $\beta 1 .{ }^{27}$ Thus, PPAR $\alpha$ and LXR $\alpha$ are physiological regulators that lie at the intersection of lipid metabolism and inflammation.

In recent years, the ingestion of naturally grown fresh vegetables, fruits, and crops was revealed to have preventive effect in diabetes and its complications. ${ }^{28}$ For example, anthocyanins are the largest group of water-soluble pigments, and belong to the family of phenolic flavonoid compounds that are responsible for the blue, red, purple, and pink colors of many plants in nature. Anthocyanins exhibit powerful antioxidative properties in diabetic animal models and also exert protective effects against hyperglycemia-induced kidney injury. ${ }^{29}$ In addition, many studies suggested that anthocyanins also have anti-inflammatory and antihyperlipidemic effects. Purple corn anthocyanins (PCA) prevent HG-induced glomerulosclerosis and renal fibrosis via NFkB-dependent mechanisms. ${ }^{8}$ Anthocyanin-rich foods and extracts increase ABCA1 levels significantly and suppress cholesterol accumulation in the liver and aorta. ${ }^{30,31}$ However, no studies have revealed the mechanisms involved in the reciprocal regulation of inflammation and cholesterol efflux by anthocyanins in DN.

In this study, we examined the effect of anthocyanins (cyanidin-3-O- $\beta$-glucoside chloride $[\mathrm{C} 3 \mathrm{G}]$ and cyanidin chloride [Cy], an aglycon of C3G; Figure 1) on HG-mediated cholesterol accumulation and inflammation, as well as their possible molecular mechanism of action in HK-2 cells.

\section{Materials and methods}

All procedures were performed in compliance with the guidelines established by the Ethics Review Committee for Experimentation of Hebei Medical University. 


\section{Reagents}

C3G (PubChem CID: 197081) and Cy (PubChem CID: 68247) were obtained from Sigma-Aldrich Co. (St Louis, MO, USA). GW6471, dimethyl sulfoxide (DMSO) and 3-(4,5-dimethylthiazol-2-y1)-2,5-diphenyltetrazoliumbromide (MTT) were purchased from Sigma-Aldrich Co. The pLV-NR1H3-shRNA plasmid was constructed by Yingrun Biotechnologies (Changsha, People's Republic of China; GenBank number NM_005693). FuGENE-HD transfection reagent was obtained from Promega (Madison, WI, USA). Antibodies against ICAM1, MCP1, PPAR $\alpha$, and NFאB p65 were obtained from Abcam (Cambridge, UK). TGF $\beta 1$ antibody was purchased from Proteintech (Chicago, IL, USA). Antibodies against LXR $\alpha$ and ABCA1 were obtained from Sangon Biotech Co, Ltd. (Shanghai, People's Republic of China). Histone H3 was purchased from Signalway Antibody (College Park, MD, USA). Human ICAM1 (H140114-19a), MCP1 (H140114-113a), and TGFß1 (H140114-17a) enzymelinked immunosorbent assay (ELISA) kits were purchased from Neobioscience (Shenzheng, People's Republic of China). TRIzol reagent and a nuclear protein extraction kit were obtained from Invitrogen (Carlsbad, CA, USA). SYBR Premix Ex TaqTMII was from TaKaRa Bio Inc. (Shiga, Japan).

\section{Cell culture}

HK-2 cells were obtained from ATCC (American Type Culture Collection, Manassas, VA, USA). They were cultured in Dulbecco's Modified Eagle's Medium/Nutrient Mixture F-12 (DMEM-F12, 3:1) supplemented with $10 \%$ fetal bovine serum in a humidified $5 \% \mathrm{CO}_{2}$ atmosphere at $37^{\circ} \mathrm{C}$. Cells were made quiescent by culturing in serum-free medium for 24 hours (h). According to the different experiments, HK-2 cells were pretreated with or without $\mathrm{C} 3 \mathrm{G}$ or $\mathrm{Cy}(50 \mu \mathrm{M})$ for $1 \mathrm{~h}$, before exposure to $\mathrm{HG}(30 \mathrm{mM})$ for 24 or $48 \mathrm{~h}$. Additional cells were stimulated with normal glucose $(\mathrm{NG})(5.6 \mathrm{mM})$ as a normal control, and NG plus mannitol $(24.4 \mathrm{mM})$ as an osmotic control. In the experiments intended to evaluate the specific involvement of PPAR $\alpha$ in the activation of its target genes, cells were treated with $25 \mu \mathrm{M}$ GW6471, a PPAR $\alpha$ antagonist, 30 minutes ( $\mathrm{min}$ ) before the treatment with anthocyanins. All cell experiments were repeated at least three times.

\section{Cell viability}

MTT assays were used to determine the effects of C3G and $\mathrm{Cy}$ on cell viability. HK-2 cells in 96 well plates were exposed to $\mathrm{HG}(30 \mathrm{mM})$ alone for $24 \mathrm{~h}$ or preincubated with different concentrations of $\mathrm{C} 3 \mathrm{G}$ and $\mathrm{Cy}(0-100 \mu \mathrm{M})$ for $1 \mathrm{~h}$, followed by stimulation with or without $\mathrm{HG}(30 \mathrm{mM})$ for $24 \mathrm{~h}$. Subsequently, $20 \mu \mathrm{L}$ MTT $(5 \mathrm{mg} / \mathrm{mL})$ was added to each well, and the cells were further incubated for an additional $4 \mathrm{~h}$. The supernatant was removed and the formazan crystals were dissolved with $150 \mu \mathrm{L} /$ well of DMSO. The optical density was measured at $570 \mathrm{~nm}$ using a microplate reader (Synergy 2; BioTek, Winooski, VT, USA).

\section{Flow cytometry}

To assess the effect of anthocyanins on HG-induced intracellular reactive oxygen species (ROS) generation in HK-2 cells, flow cytometry with CM-DCHF-DA (CM-DCHF-DA" is chloromethyl-2', $7^{\prime}$-dichlorodihydrofluorescein diacetate; Invitrogen) was used to evaluate the changes in hydroxyl radicals quantitatively. Briefly, cells were grown to $60 \%-70 \%$ confluence, and then incubated under the different experimental conditions in 6 well plates for $48 \mathrm{~h}$. The media was then replaced with fresh serum-free media containing $10 \mu \mathrm{M}$ DCHF-DA at $37^{\circ} \mathrm{C}$ for $30 \mathrm{~min}$. Thereafter, cells were washed, trypsinized, and suspended in $500 \mu \mathrm{L}$ phosphate-buffered saline (PBS), and the fluorescence intensity was measured immediately using a flow cytometer (BD Immunocytometry Systems, Franklin Lakes, NJ, USA).

\section{Transient transfection}

HK-2 cells were transfected transiently using FuGENE-HD transfection reagent according to the manufacturer's instructions. Cells were seeded in 6 well plates at $80 \%$ confluence, and then transfected with $3.0 \mu \mathrm{g}$ pLV-NR1H3-shRNA plasmid or scrambled control shRNA plasmid with $9 \mu \mathrm{L}$ transfection reagent in $2 \mathrm{~mL}$ normal DMEM-F12 (3:1) medium. After $24 \mathrm{~h}$, the cells were washed once with serum-free DMEM-F12 (3:1) medium, treated with $\mathrm{HG}$ or $\mathrm{HG}$ plus anthocyanins for $48 \mathrm{~h}$, and then analyzed using Western blotting and filipin staining.

\section{ELISA assay}

The supernatants from different groups of cells were collected and the concentrations of the proinflammatory cytokines, ICAM1, MCP1, and TGF $\beta 1$, were quantified using commercially available ELISA kits (Neobioscience), according to the manufacturer's instructions.

\section{Western blotting}

Nuclear and cytoplasmic proteins were extracted from HK-2 cells using a Nuclear and Cytoplasmic Protein Extraction Kit (Invitrogen). Proteins $(50 \mu \mathrm{g} / \mathrm{lane})$ were separated by sodium dodecyl sulfate-polyacrylamide gel electrophoresis (SDS-PAGE), and transferred to polyvinylidene difluoride membranes (Millipore, Billerica, MA, USA). The membranes were incubated overnight at $4^{\circ} \mathrm{C}$ with anti-ABCA1, -PPAR $\alpha$, -LXR $\alpha$, -MCP1, -ICAM1, -TGF $\beta 1$, - $\beta$-actin, and -histone H3 
Table I Primer sequences used for real-time polymerase chain reaction

\begin{tabular}{llll}
\hline Gene & Forward primer & Reverse primer & Product (base pair) \\
\hline PPAR $\alpha$ & AGAAGCTGTCACCACAGTAGC & CGCGTGGACTCCGTAATGAT & 132 \\
ABRA $\alpha$ GCTGAAGACCTCTGCGATCG & CAAGGCAAACTCGGCATCA & 108 \\
$I C A M I$ & GCACTGAGGAAGATGCTGAAA & AGTTCCTGGAAGGTCTTGTTCAC & 144 \\
$M C P I$ & CGCTGCCCGCACTCCTGGTC & CATGTCACCAGCACGGAGCC & 117 \\
TGF $\beta I$ & CGCCCTTCTGTGCCTGCTGCTC & CTGGTGATTCTTCTATAGCTCGCG & 152 \\
$I 8 S$ & GCCGACTACTACGCCAAGGAGG & CTTCTCGGAGCTCTGATGTGTTG & 126 \\
\hline
\end{tabular}

antibodies. Next, the membranes were incubated with goat anti-rabbit or mouse IgG horseradish peroxidase-conjugated secondary antibodies, and then scanned using an Odyssey Fc System (LI/-COR; Amersham, Piscataway, NJ, USA). The intensity of the bands was measured using LabWorks 4.5 software (UVP, Upland, CA, USA).

\section{RNA isolation and quantitative real-time polymerase chain reaction (RT-qPCR)}

Total RNA and cDNA were prepared from cultured cells using TRIzol reagent (Invitrogen) and a TaKaRa RNA PCR kit (AMV) version 3.0 (TaKaRa Bio Inc.), respectively. cDNA was amplified using PCR with specific primers for PPAR $\alpha, L X R \alpha, A B C A 1, M C P 1, I C A M 1, T G F \beta 1$, and $18 s$ rRNA (Table 1). RT-qPCR was performed using SYBR Premix Ex TaqTMII and an Agilent Mx3000P QPCR System (Agilent, CA, USA). The relative changes in gene expression were calculated using the $2^{-\Delta \Delta C T}$ method, and all experiments were repeated at least thrice.

\section{Oil Red $O$ staining}

HK-2 cells were allowed to adhere to polylysine-coated coverslips and grown for $24 \mathrm{~h}$. Cells were pretreated with or without $\mathrm{C} 3 \mathrm{G}$ or $\mathrm{Cy}(50 \mu \mathrm{M})$ for $1 \mathrm{~h}$, and then exposed to $\mathrm{HG}(30 \mathrm{mM})$ for 24 or $48 \mathrm{~h}$. Subsequently, total cellular cholesterol was measured using Oil Red $\mathrm{O}$ staining. Cells were fixed in 4\% paraformaldehyde in PBS for $30 \mathrm{~min}$ and then stained for $15 \mathrm{~min}$ in $1 \%$ Oil Red O dissolved in 60\% isopropanol. Then, the sections were washed with $70 \%$ alcohol for 5 seconds (s) to remove background staining. Finally, the cells were rinsed in tap water and counterstained with Harris hematoxylin for $10 \mathrm{~s}$. The stained sections were imaged with an Olympus microscope (Olympus Corporation, Tokyo, Japan).

\section{Cholesterol efflux assays}

Cholesterol levels were assayed using an Amplex Red Cholesterol Assay kit (Molecular Probes; Invitrogen) according to the manufacturer's instructions. Briefly, HK-2 cells were treated as described above in 96 well plates, and then $50 \mu \mathrm{L}$ Amplex Red reagent was added. After 45 min incubation at $37^{\circ} \mathrm{C}$ in the dark, sample fluorescence was measured using a microplate reader (Synergy 2; BioTek) with excitation at 530/525 $\mathrm{nm}$ and emission at 590/535 nm. Both the extracellular (in the growth medium) and intracellular cholesterol were analyzed. Cholesterol esterase was omitted from the assay. Each sample was analyzed in triplicate, and at least three independent experiments were performed.

\section{Immunocytochemistry}

Endogenous peroxidase activity was blocked using 3\% hydrogen peroxide for $10 \mathrm{~min}$, and the cells were incubated overnight at $4^{\circ} \mathrm{C}$ with anti-NFKB p65 (1:100) monoclonal antibody. Subsequently, the cells were incubated with biotin-labeled anti-rabbit IgG for $1 \mathrm{~h}$, and then stained using a streptavidinperoxidase detection system. Negative control samples were incubated with PBS instead of the primary antibody.

\section{Statistical analysis}

Values are expressed as means \pm SDs. Significant differences between groups were determined using one-way analysis of variance using SAS software (release 8.01; SAS Institute, Inc., Cary, NC, USA); $P<0.05$ was considered to be statistically significant.

\section{Results}

\section{Effect of anthocyanins on cell viability and radical scavenging}

The potential cytotoxic effects of anthocyanins were evaluated first using MTT assays. The results showed that $\mathrm{C} 3 \mathrm{G}$ and Cy did not affect the viability of $\mathrm{HK}-2$ cells at the concentrations used (10, 20, and $50 \mu \mathrm{M}$; Figure 2A and B). Thus, C3G and Cy did not have cytotoxic effects in HK-2 cells. Because anthocyanins have powerful antioxidative properties, we next evaluated whether $\mathrm{C} 3 \mathrm{G}$ and $\mathrm{Cy}$ reduced $\mathrm{HG}$-induced ROS production in $\mathrm{HK}-2$ cells, and the doses required for these effects. As shown in Figure 2C and D, HG increased intracellular ROS levels significantly, and this effect was reduced by $\mathrm{C} 3 \mathrm{G}$ and $\mathrm{Cy}$ in a dose-dependent manner. These results indicate that $\mathrm{C} 3 \mathrm{G}$ and Cy could reduce the intracellular ROS levels effectively 

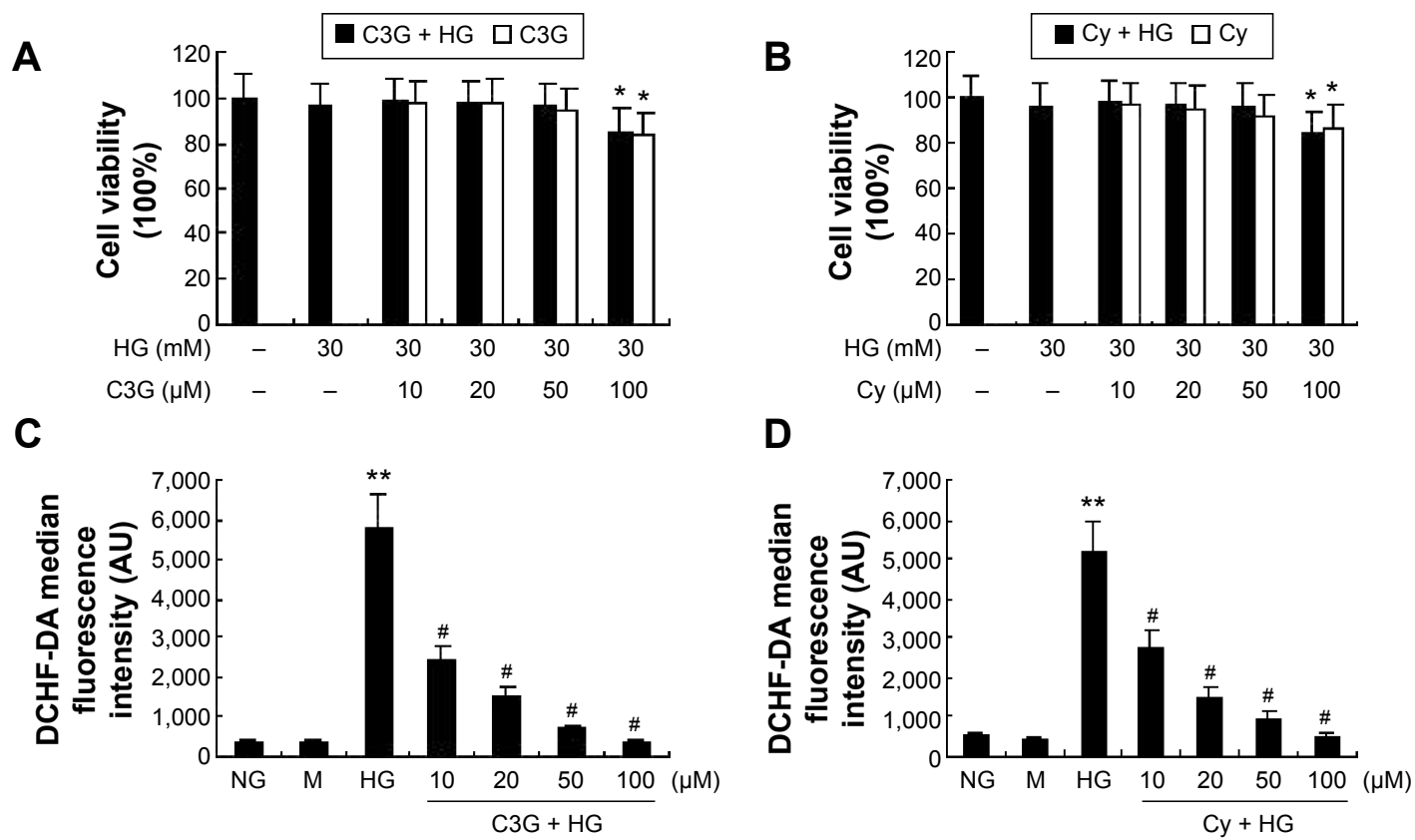

Figure 2 Effects of C3G and Cy on the cell viability and ROS levels in HK-2 cells.

Notes: Cytotoxic effects of C3G (A) and Cy (B) on HK-2 cells was determined by MTT assay. Cells were cultured with different concentrations of C3G and Cy (0-100 $\mu$ M) in the absence or presence of $30 \mathrm{mM} \mathrm{HG}$ for $24 \mathrm{~h}$. The values presented are the means $\pm S D$ of three independent experiments. $* P<0.05$ versus control group. Effects of $C 3 \mathrm{G}$ (C) and Cy (D) on radical scavenging activity in HG-stimulate HK-2 cells. Cells were preincubated with or without different concentrations of $C 3 \mathrm{G}$ and $\mathrm{Cy}(0-100 \mu \mathrm{M})$ for I $\mathrm{h}$ and then treated with $30 \mathrm{mM} \mathrm{HG}$ for $24 \mathrm{~h}$. Quantification of the ROS levels as detected by flow cytometry. The values presented are the means \pm SD of three independent

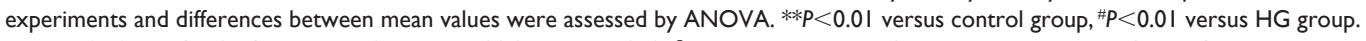

Abbreviations: ANOVA, analysis of variance; C3G, cyanidin-3-O- $\beta$-glucoside chloride; Cy, cyanidin chloride; DCHF-DA, dichlorodihydrofluorescein diacetate; h, hour/s; HG, high-glucose; M, mannitol; NG, normal glucose; ROS, reactive oxygen species.

in a dose-dependent manner under HG conditions. Taken together with the results of MTT assays, we selected the dose of $50 \mu \mathrm{M}$ of anthocyanins for use in subsequent experiments. In addition, mannitol had no effect on ROS levels.

\section{Anthocyanins enhance cholesterol efflux and $A B C A$ I expression in HG-stimulated HK-2 cells}

To determine whether anthocyanins weakened or prevented HG to decrease cholesterol efflux, we first analyzed cholesterol levels inside the cell using Oil Red O staining. Compared with the NG groups, HG enhanced cholesterol levels significantly inside the cell after treatment for $24 \mathrm{~h}$, and this continued to increase until $48 \mathrm{~h}$. In contrast, treatment with C3G and Cy markedly attenuated HG-induced cholesterol levels increasing inside the cell (Figure 3A). Next, we investigated the changes in cholesterol concentrations in the culture media and inside the cell using cholesterol efflux analysis. The results were consistent with Oil Red O staining (Figure 3B and C).

Because ABCA1 is important for cholesterol efflux, ${ }^{16}$ we next examined the effect of anthocyanins on ABCA1 expression. The mRNA and protein levels of ABCA1 significantly decreased after treatment with $\mathrm{HG}$ for $24 \mathrm{~h}$, and remained at low levels until $48 \mathrm{~h}$. Treatment with $\mathrm{C} 3 \mathrm{G}$ and $\mathrm{Cy}$ reversed the HG-induced decrease in ABCA1 markedly (Figure 3D and E). These results suggest that anthocyanins enhanced cholesterol efflux from HK-2 cells by upregulating ABCA1.

\section{Anthocyanins increase the gene expression of PPAR $\alpha$ and $L X R \alpha$ in HG-stimulated HK-2 cells}

To investigate the potential mechanism by which anthocyanins induce ABCA1 expression upregulation and cholesterol efflux, we analyzed the expression of PPAR $\alpha$ and LXR $\alpha$. As shown in Figure 4, HG treatment decreased the protein and mRNA expression of PPAR $\alpha$ and LXR $\alpha$ at 24 and $48 \mathrm{~h}$, respectively. Treatment with $50 \mu \mathrm{M} \mathrm{C} 3 \mathrm{G}$ and $\mathrm{Cy}$ reversed HG-induced decreased protein (Figure 4A) and mRNA (Figure 4B) PPAR $\alpha$ and LXR $\alpha$ levels markedly.

\section{The upregulating of $A B C A I$ gene expression by anthocyanins is dependent on PPAR $\alpha / L X R \alpha$ in HG-stimulated HK-2 cells}

We first treated HK-2 cells with both $\mathrm{HG}$ and $\mathrm{C} 3 \mathrm{G}$ or $\mathrm{Cy}$ in the presence of $25 \mu \mathrm{M} \mathrm{GW6471} \mathrm{(PPAR} \alpha$ inhibitor) and 
A

NG

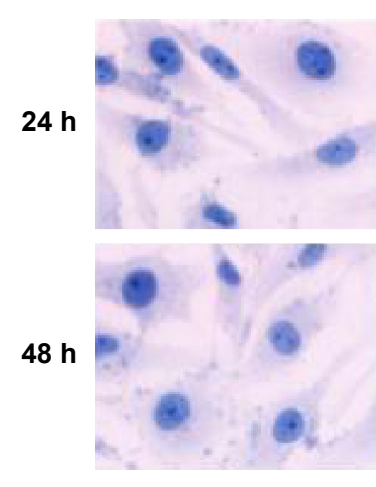

HG

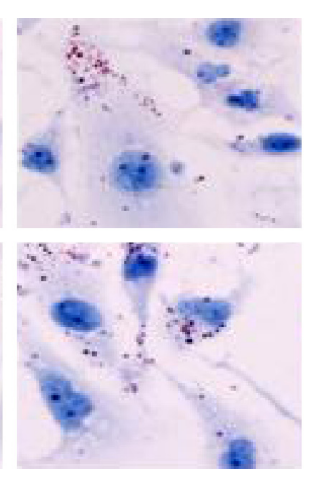

C3G + HG

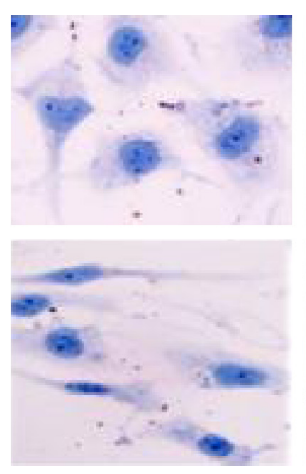

Cy + HG

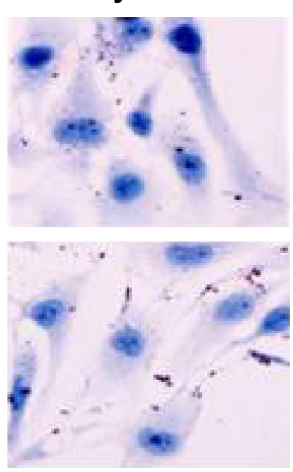

B

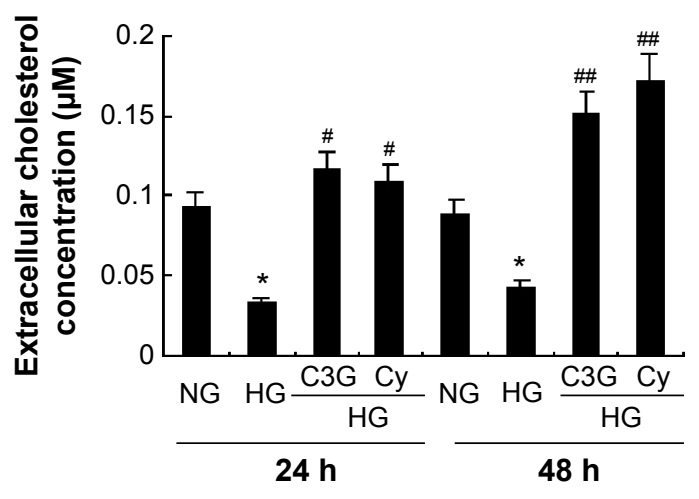

D

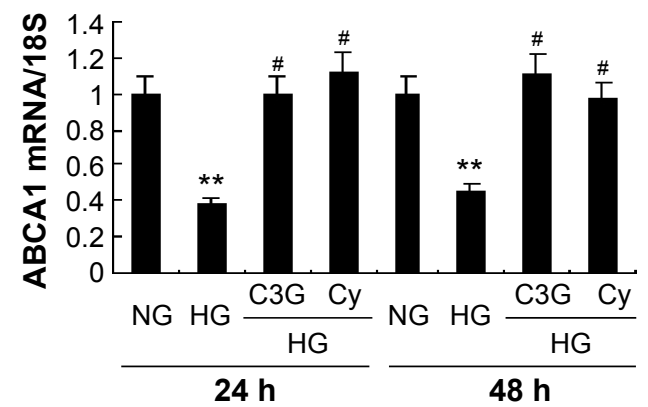

C
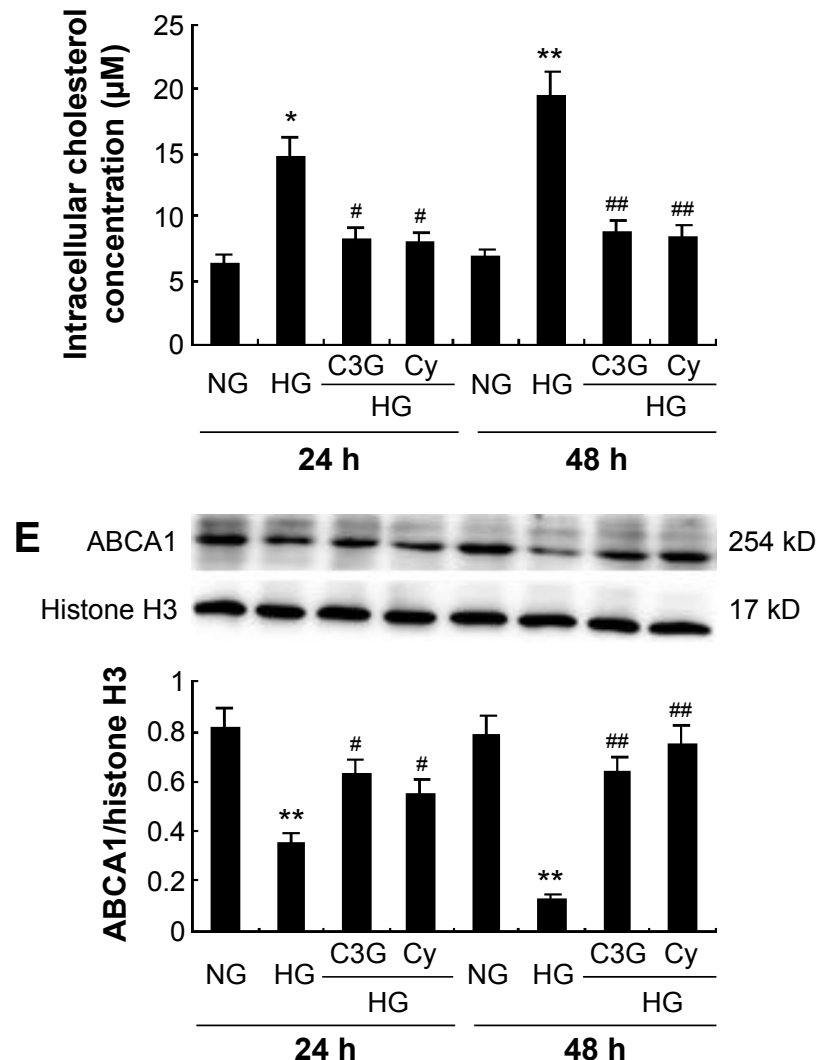

Figure 3 Anthocyanins enhance cholesterol efflux and ABCAI expression in HG-stimulated HK-2 cells.

Notes: Cells were preincubated with or without C3G and Cy $(50 \mu \mathrm{M})$ for I h and then treated with $30 \mathrm{mM}$ HG for 24 or 48 h. (A) Cholesterol mass inside the cell was measured by Oil Red staining. (B and C) Effect of C3G and Cy on cholesterol concentration in the medium (B) and intracellularly (C) was assayed by an Amplex Red Cholesterol Assay kit. (D) The expression levels of ABCAI mRNA were analyzed by RT-qPCR. (E) The expression levels of ABCAI protein were detected by Western blot. The values presented are the means \pm SD of three independent experiments. ${ }^{*} P<0.05,{ }^{* *} P<0.0 \mathrm{I}$ versus control group, ${ }^{\# P} P 0.05$, ${ }^{\# P} P<0.0 \mathrm{I}$ versus $H G$ group.

Abbreviations: C3G, cyanidin-3-O- $\beta$-glucoside chloride; Cy, cyanidin chloride; h, hour/s; HG, high-glucose; NG, normal glucose; RT-qPCR, quantitative real-time polymerase chain reaction.

observed the effect of GW6471 on $L X R \alpha$ and $A B C A 1$ gene expression and cholesterol efflux. The results showed that GW6471 reduced LXR $\alpha$ and ABCA1 expression compared with the NG group. The coincubation of anthocyanins and GW6471 blocked the anthocyanin-induced increase in LXR $\alpha$ and ABCA1 protein (Figure 5A) and mRNA (Figure 5B) expression and the cholesterol efflux (Figure 5C and D).
These results suggest that anthocyanins induce $A B C A 1$ gene expression via the PPAR $\alpha$ pathway.

Next, we used transfection to determine the effects of silencing $\mathrm{LXR} \alpha$ on anthocyanin-induced $A B C A 1$ gene expression and cholesterol efflux. Compared with scrambled control shRNA, LXR $\alpha$ shRNA suppressed LXR $\alpha$ expression by $76 \%(P<0.01$; Figure $6 \mathrm{~A})$. In addition, silencing $\mathrm{LXR} \alpha$ 
A
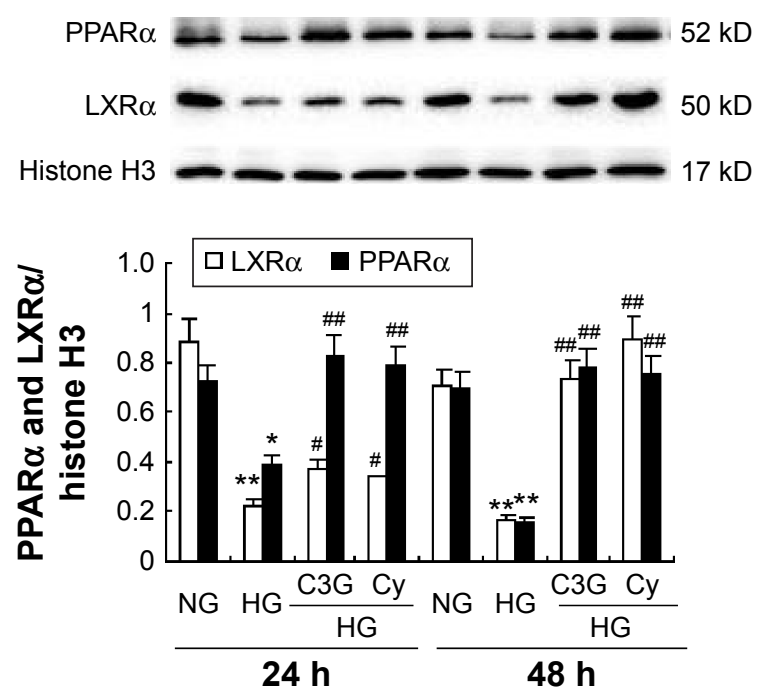

B
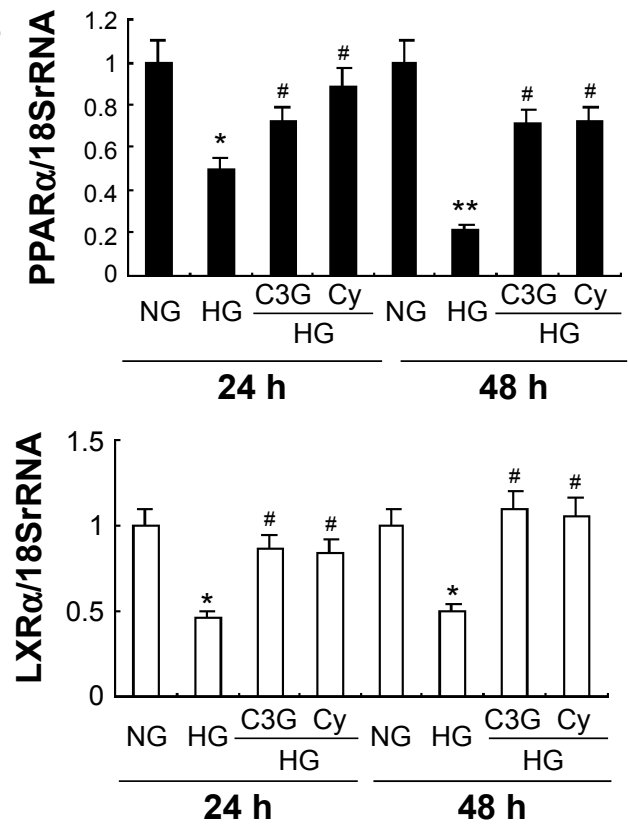

Figure 4 Effects of anthocyanins on HG-induced PPAR $\alpha$ and $L X R \alpha$ expression in HK-2 cells.

Notes: Cells were preincubated with or without C3G and Cy $(50 \mu \mathrm{M})$ for I h and then treated with $30 \mathrm{mM}$ HG for 24 or $48 \mathrm{~h}$. (A) The expression levels of PPAR $\alpha$ and LXR $\alpha$ protein were detected by Western blot. (B) The expression levels of PPAR $\alpha$ and LXR $\alpha$ mRNA were analyzed by RT-qPCR. The values presented are the mean \pm SD of three independent experiments. ${ }^{*} P<0.05$, ${ }^{* * P}<0.0$ I versus control group, ${ }^{*} P<0.05,{ }^{\#} P<0.0$ I versus $\mathrm{HG}$ group.

Abbreviations: C3G, cyanidin-3-O- $\beta$-glucoside chloride; Cy, cyanidin chloride; h, hour/s; HG, high-glucose; NG, normal glucose; RT-qPCR, quantitative real-time polymerase chain reaction.

reversed the effects of anthocyanins on ABCA1 expression (Figure 6B and $\mathrm{C}$ ) and cholesterol efflux (Figure 6D). These results indicate that anthocyanins increase ABCA1 expression and cholesterol efflux via an LXR $\alpha$-dependent pathway.

\section{Effects of anthocyanins on cytokine production in HG-stimulated HK-2 cells}

To analyze the anti-inflammatory effects of anthocyanins in the progression of the $\mathrm{DN}$, we measured the protein and mRNA levels of ICAM1, MCP1, and TGF $\beta 1$ using Western blotting, quantitative real-time (qRT)-PCR, and ELISA. Western blotting analysis revealed that HG increased the protein levels of ICAM1, MCP1, and TGF $\beta 1$ at 24 and $48 \mathrm{~h}$ significantly compared with NG group. In contrast, these HGinduced increases were decreased significantly by $\mathrm{C} 3 \mathrm{G}$ and $\mathrm{Cy}$ (Figure 7A). The results of qRT-PCR (Figure 7B) and ELISA (Figure 7C) were consistent with these observations.

\section{The anthocyanin-induced reduction in} ICAMI, MCPI, and TGF $\beta$ I expression is dependent on the activation of $L X R \alpha$, but not PPAR $\alpha$

Recent reports ${ }^{22-26}$ demonstrated that PPAR $\alpha$ and LXR $\alpha$ mediated the expression of some inflammatory cytokines.
Therefore, we next investigated the possible effects of PPAR $\alpha$ and LXR $\alpha$ on the inhibition of HG-mediated inflammatory signaling by anthocyanins. First, HK-2 cells were transfected with pLV-NR1H3-shRNA plasmid and then incubated with $\mathrm{HG}$ in the presence or absence of $\mathrm{C} 3 \mathrm{G}$ or Cy for $48 \mathrm{~h}$. Compared with the anthocyanin treatment groups, transfection with pLV-NR1H3-shRNA reversed the effects of anthocyanins on HG-induced ICAM1, MCP1, and TGF $\beta 1$ expression significantly (Figure 8A and B). Next, we used the specific PPAR $\alpha$ inhibitor GW6471 to observe the role of PPAR $\alpha$ in the anthocyanin-mediated inhibition of HG-induced ICAM1, MCP1, and TGF $\beta 1$ expression. Co-pretreatment with $25 \mu \mathrm{M}$ GW6471 and $\mathrm{C} 3 \mathrm{G}$ or Cy for $48 \mathrm{~h}$ slightly reversed the inhibitory effects of $\mathrm{C} 3 \mathrm{G}$ or $\mathrm{Cy}$ on HG-induced ICAM1, MCP1, and TGF $\beta 1$ expression (Figure 8A and B). These results suggest that anthocyanins decreased the expression of ICAM1, MCP1, and TGF $\beta 1$ by upregulating $\mathrm{LXR} \alpha$ transcriptional activity, but not PPAR $\alpha$.

\section{Effects of anthocyanins on NFKB}

\section{activation in HG-stimulated $\mathrm{HK}-2$ cells}

As shown in Figure 9, HG enhanced the nuclear and decreased the cytoplasmic localization of NFkB p65 $(P<0.05)$. However, HG-induced NFKB p65 nuclear translocation was 
A
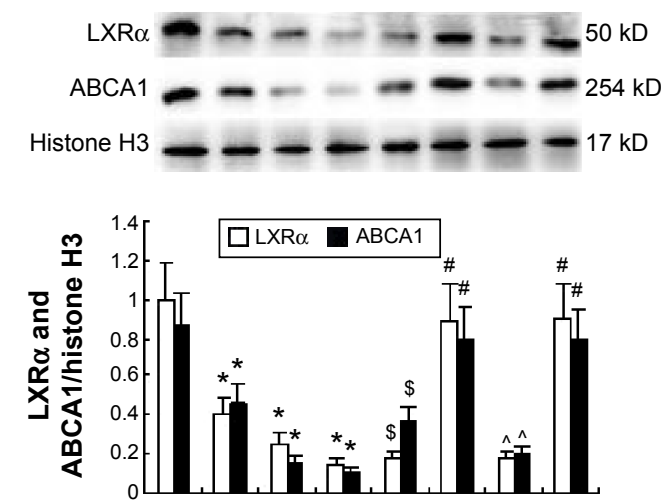

$\mathrm{HG}(30 \mathrm{mM})-+\quad+++++$ GW6471 $(25 \mu \mathrm{M})-{ }_{-}+++\ldots+$

C3G $(50 \mu \mathrm{M})-\quad-\quad-\quad+\quad+-$

Cy $(50 \mu \mathrm{M})$
C

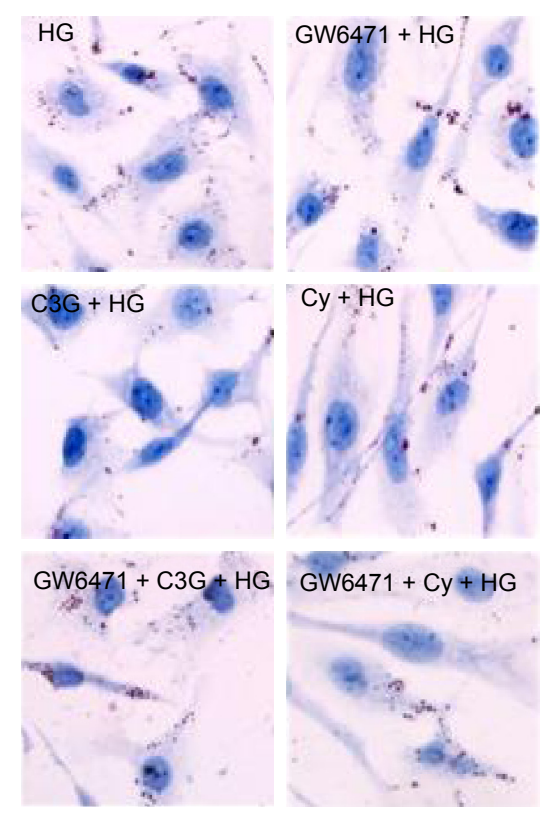

B

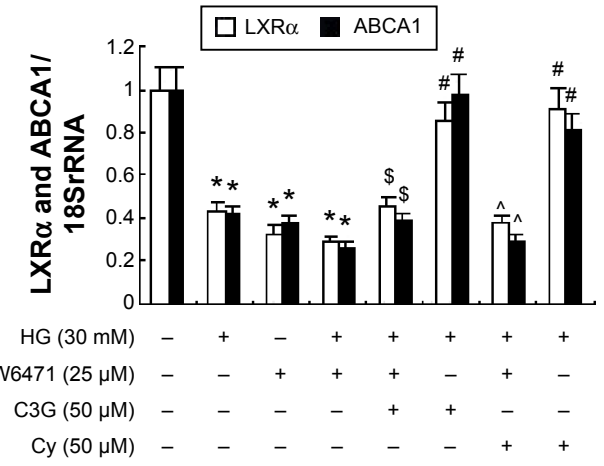

D

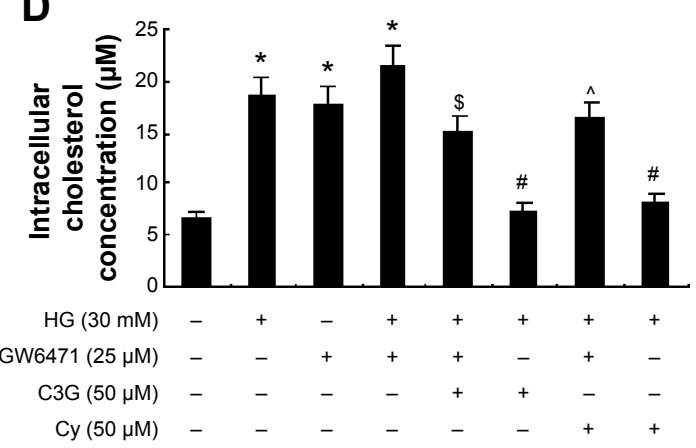

Figure 5 Effects of GW647I on anthocyanins-induced $L X R \alpha$ and $A B C A$ I gene expression and the cholesterol efflux in HK-2 cells.

Notes: Cells were preincubated with both GW647I ( $25 \mu \mathrm{M})$ and C3G or Cy for I h, followed by treatment with 30 mM HG for 48 h. (A) The expression levels of LXR $\alpha$ and $A B C A I$ protein were detected by Western blot. (B) The expression levels of $L X R \alpha$ and $A B C A I$ mRNA were analyzed by RT-qPCR. (C) Cholesterol mass inside the cell was measured by Oil Red staining. (D) Cholesterol concentration in cells was assayed by an Amplex Red Cholesterol Assay kit. The values presented are the mean \pm SD of three independent experiments. ${ }^{*} P<0.01$ versus control group, ${ }^{\sharp} P<0.05$ versus $\mathrm{HG}$ group. ${ }^{\$} P<0.05$ versus $\mathrm{HG}+\mathrm{C} 3 \mathrm{G}$ group, $\wedge P<0.01$ versus $\mathrm{HG}+\mathrm{Cy}$ group.

Abbreviations: C3G, cyanidin-3-O- $\beta$-glucoside chloride; Cy, cyanidin chloride; h, hour/s; HG, high-glucose; RT-qPCR, quantitative real-time polymerase chain reaction.

attenuated by $\mathrm{C} 3 \mathrm{G}$ and $\mathrm{Cy}(I<0.05)$, which suggests that the anti-inflammatory effects of anthocyanins are most likely mediated by NFKB signaling.

\section{Anthocyanin-induced NFאB activity reduces cytokine production via the $\mathrm{LXR} \alpha$ pathway}

To test whether NFKB activation involved in the antiinflammatory effects of anthocyanins is mediated by the LXR $\alpha$ pathway, we next detected the expression of NFKB p65 when LXR $\alpha$ was silenced in HK-2 cells using pLVNR1H3-shRNA plasmid. As expected, the inhibitory effect of anthocyanins on NFKB activity was reversed markedly by transfection with pLV-NR1H3-shRNA (Figure 10A). We then used immunocytochemistry to investigate the nuclear translocation of NFkB p65. Data revealed that NFkB p65 was localized predominately in the cytoplasm in control cells, whereas HG treatment caused pronounced NF $\kappa B$ p 65 nuclear staining. However, $\mathrm{C} 3 \mathrm{G}$ and $\mathrm{Cy}$ decreased the nuclear distribution of NFkB p65 (Figure 10B). Moreover, transfection with pLV-NR1H3-shRNA led to predominantly nuclear NFKB p65 staining after HG treatment. Taken together, these data suggest that anthocyanins inhibit HG-induced inflammatory gene expression by activating LXR $\alpha$ and affecting the nuclear translocation of NFKB.

\section{Discussion}

The drugs used to treat diabetes and its complications often cause a variety of side effects. Therefore, increasing attention has focused on studying phytochemicals that are easy to obtain and lack numerous side effects. ${ }^{27}$ Anthocyanins are naturally occurring phytochemicals and are widely distributed in vegetables, 
A
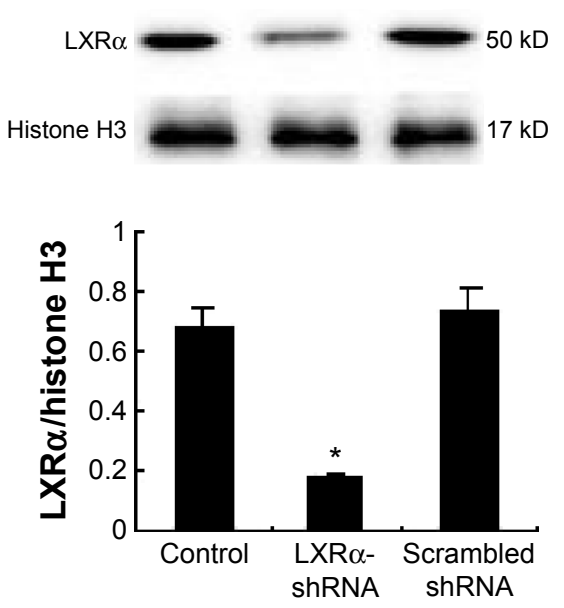

C

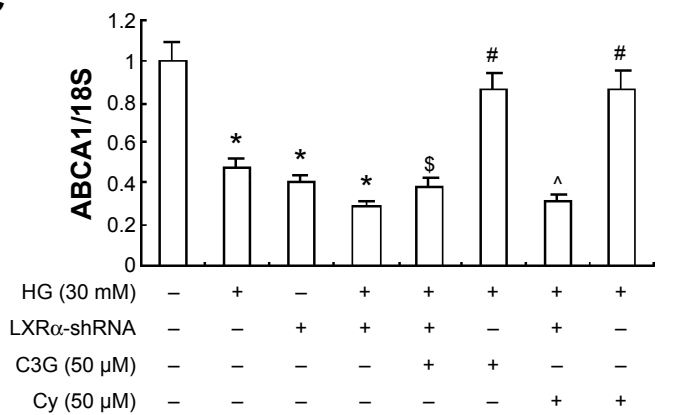

B
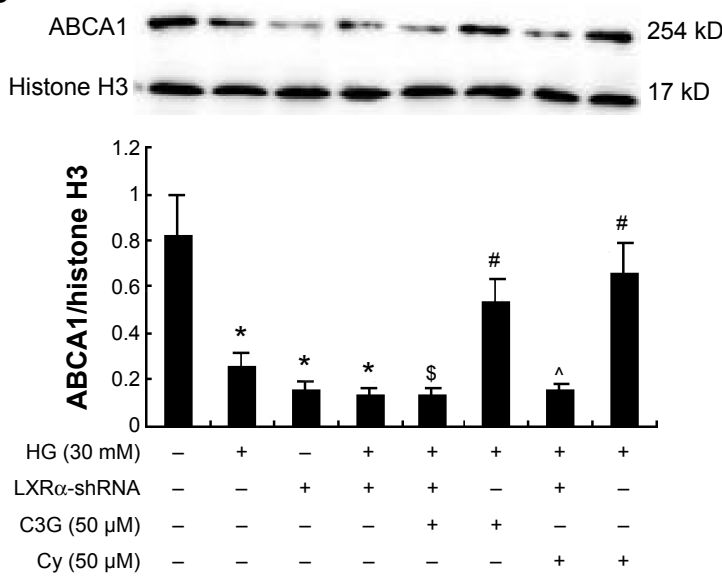

D

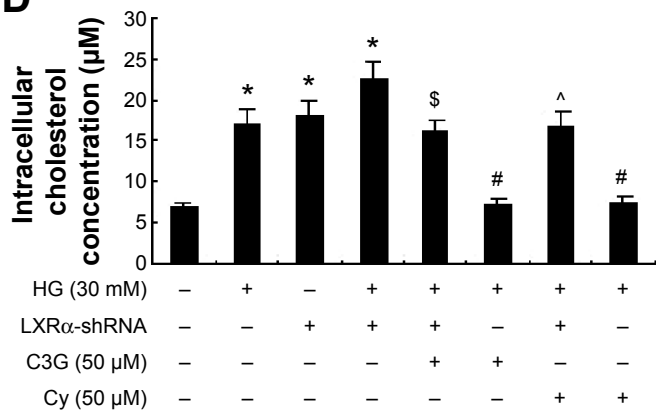

Figure 6 Knockdown of $L X R \alpha$ abrogated the anthocyanins-induced $A B C A$ I gene expression and the cholesterol efflux in HK-2 cells.

Notes: Cells were transfected with pLV-NRIH3-shRNA plasmid or scrambled control shRNA plasmid for $24 \mathrm{~h}$ and then treated with HG (30 Mm) in the presence or absence of C3G and Cy $(50 \mu \mathrm{M})$ for $48 \mathrm{~h}$, respectively. (A) The effect of pLV-NRIH3-shRNA plasmid on LXR $\alpha$ expression was detected by Western blotting. (B) The expression levels of ABCAI protein were detected by Western blot. (C) The expression levels of ABCAI mRNA were analyzed by RT-qPCR. (D) Cholesterol concentration in cells was assayed by an Amplex Red Cholesterol Assay kit. The values presented are the mean \pm SD of three independent experiments. $* P<0.0$ I versus control group, ${ }^{\#} P<0.05$ versus $H G$ group. ${ }^{\$} P<0.05$ versus $H G+C 3 G$ group, $\wedge P<0.01$ versus $H G+C y$ group.

Abbreviations: C3G, cyanidin-3-O- $\beta$-glucoside chloride; $C y$, cyanidin chloride; h, hour/s; HG, high-glucose; RT-qPCR, quantitative real-time polymerase chain reaction.

fruits, and grains; therefore, a high daily intake (180-250 $\mathrm{mg} /$ day) can be achieved from plant-based diets. Glycosides of aglycon cyanidin are the most abundant anthocyanin, and cyanidin might be obtained from cyanidin-glycosides via bacterial $\beta$-glycosidase-catalyzed hydrolysis. ${ }^{32}$ Hou et a ${ }^{33}$ reported that cyanidin and cyanidin-glycosides have antioxidant properties in living systems. Recently, several studies demonstrated that $\mathrm{C} 3 \mathrm{G}$ has potential antidiabetic and anti-inflammatory effects. ${ }^{34-36}$ However, it was unclear whether cyanidin has similar effects. Therefore, we assessed the effects of $\mathrm{C} 3 \mathrm{G}$ and Cy on HG-induced cholesterol accumulation and inflammation in HK-2 cells. Data revealed that $\mathrm{C} 3 \mathrm{G}$ and Cy decreased cholesterol accumulation by activating PPAR $\alpha$ and LXR $\alpha$ to increase the expression of $\mathrm{ABCA} 1$. In addition, $\mathrm{C} 3 \mathrm{G}$ and Cy inhibited the production of the proinflammatory cytokines MCP1, ICAM1, and TGF $\beta 1$ by activating LXR $\alpha$ and inhibiting the nuclear translocation of NFKB. These results suggest that anthocyanins might have important implications toward preventing diabetes-associated kidney injury.
Recent work suggested that decreased cellular cholesterol efflux contributes to the progression of DN. Renal cholesterol accumulation was reported in podocytes, ${ }^{37}$ diabetic NOD mice, ${ }^{16}$ and an animal model of acute renal tubular injury. ${ }^{17} \mathrm{ABCA} 1$ is a well-characterized cholesterol transporter that regulates cellular lipid homeostasis. ${ }^{16,17}$ Some reports showed that anthocyanins significantly ameliorated hypercholesterolemia and suppressed cholesterol accumulation by upregulating ABCA1 in the liver and aorta, suggesting the anthocyanins might remove cholesterol from tissues. ${ }^{29,30}$ Preclinical studies revealed that dietary anthocyanin-rich extracts ameliorated hyperglycemia and hyperlipidemia in high-fructose-fed rats and experimental type 2 diabetic mice. ${ }^{38,39}$ Here, we showed that HG inhibited cholesterol efflux and increased the intracellular cholesterol content in HK-2 cells significantly, which was accompanied by reduced ABCA1 expression. $\mathrm{C} 3 \mathrm{G}$ and Cy treatment reversed these effects: increased ABCA1 mRNA and protein expression and intracellular cholesterol 
A
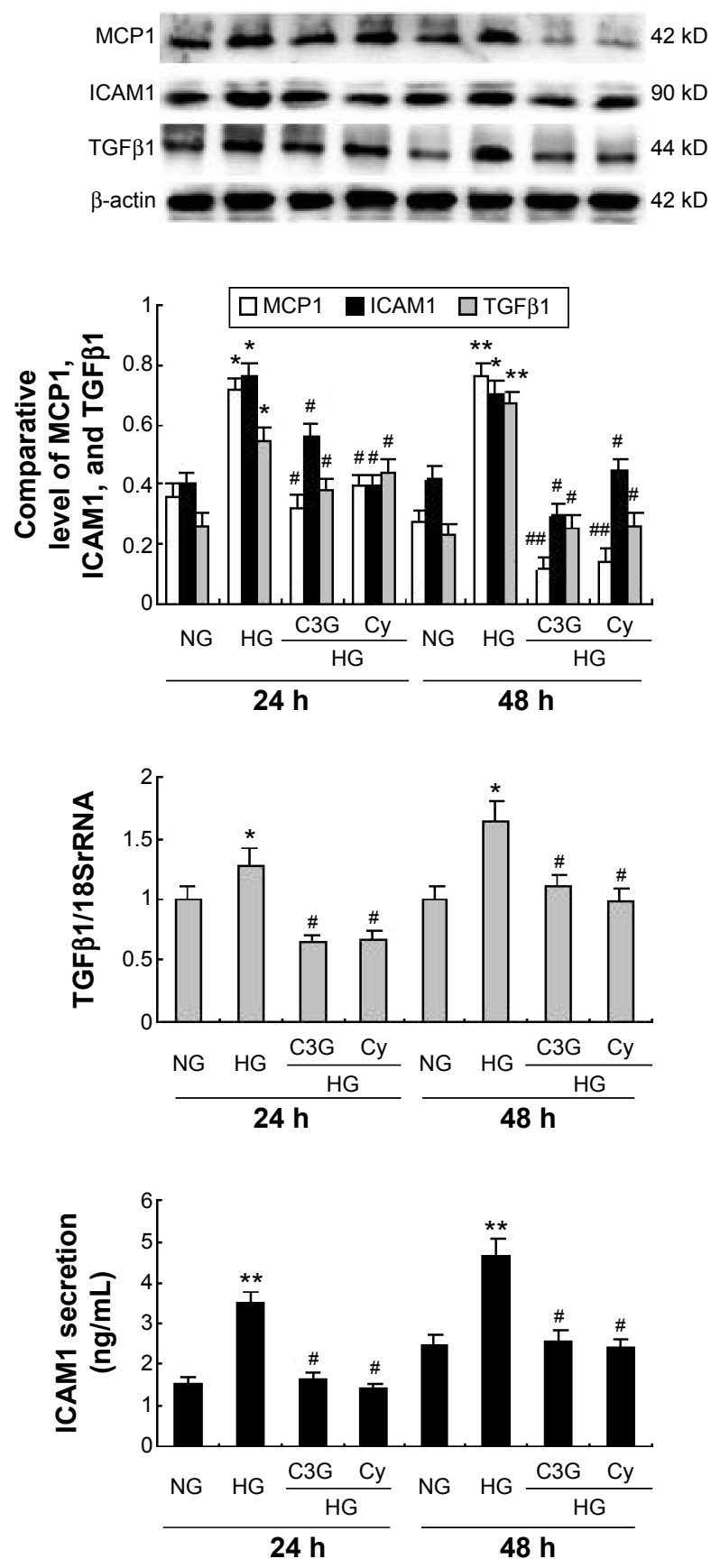

B
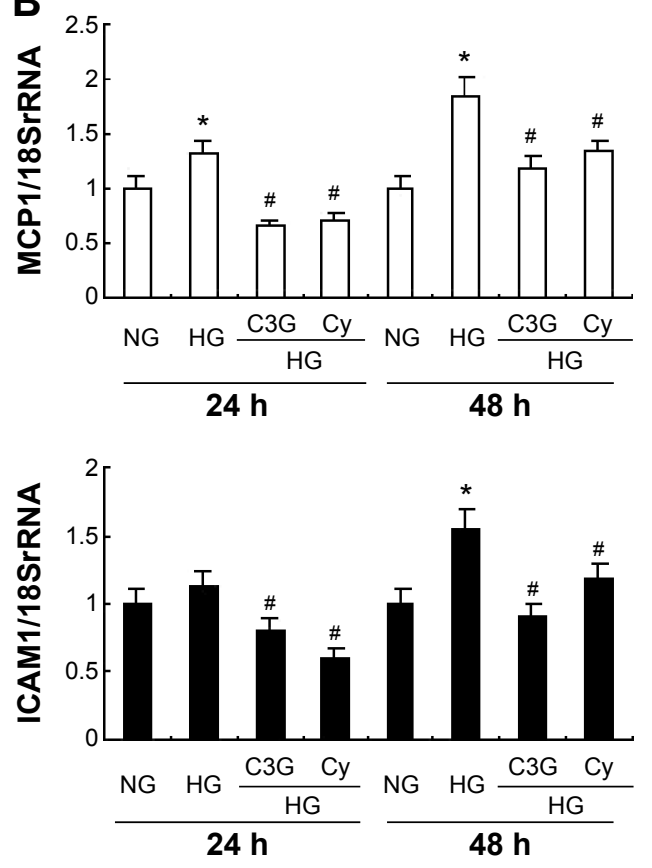

C
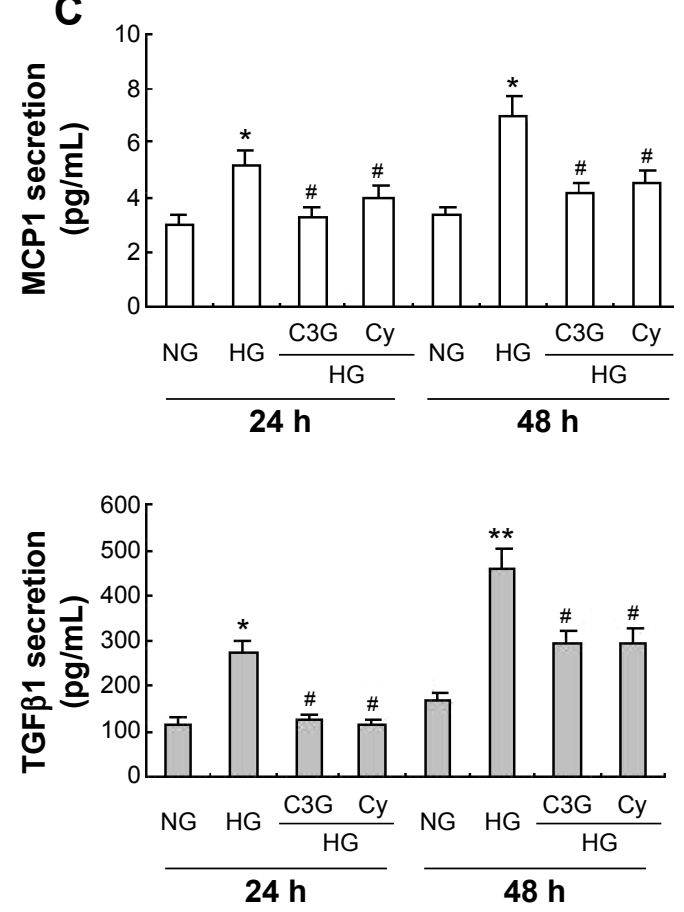

Figure 7 Effects of anthocyanins on HG-induced MCPI, ICAMI, and TGF $\beta$ I expression in HK-2 cells.

Notes: Cells were preincubated with or without C3G and Cy $(50 \mu \mathrm{M})$ for I h and then treated with $30 \mathrm{mM}$ HG for 24 or 48 h. The expression levels of MCPI, ICAMI, and TGF $\beta$ I protein were detected by Western blot $(\mathbf{A})$ and mRNA was analyzed by RT-qPCR (B). Levels of MCPI, ICAMI, and TGF $\beta$ I in culture supernatants were measured by ELISA (C). The values presented are the mean \pm SD of three independent experiments. $* P<0.05$, $* * P<0.01$ versus control group, ${ }^{*} P<0.05$, $P<0.01$ versus $H G$ group. Abbreviations: C3G, cyanidin-3-O- $\beta$-glucoside chloride; Cy, cyanidin chloride; h, hour/s; HG, high-glucose; NG, normal glucose; RT-qPCR, quantitative real-time polymerase chain reaction; ELISA, enzyme-linked immunosorbent assay.

efflux were observed in HK-2 cells cotreated with HG and anthocyanins.

The levels of proinflammatory cytokines such as ICAM1, MCP1, and TGF $\beta 1$ are elevated in diabetic kidneys, suggesting that renal inflammation might contribute to the pathogenesis of DN. ${ }^{6-9}$ Recent studies focused on the anti-inflammatory properties of anthocyanins for application in a large number of inflammatory diseases. $\mathrm{C} 3 \mathrm{G}$ inhibited the expression of TNF $\alpha$, IL1 $\beta$, IL6, IL10, and IFN $\beta$ in LPS-stimulated alveolar 
A
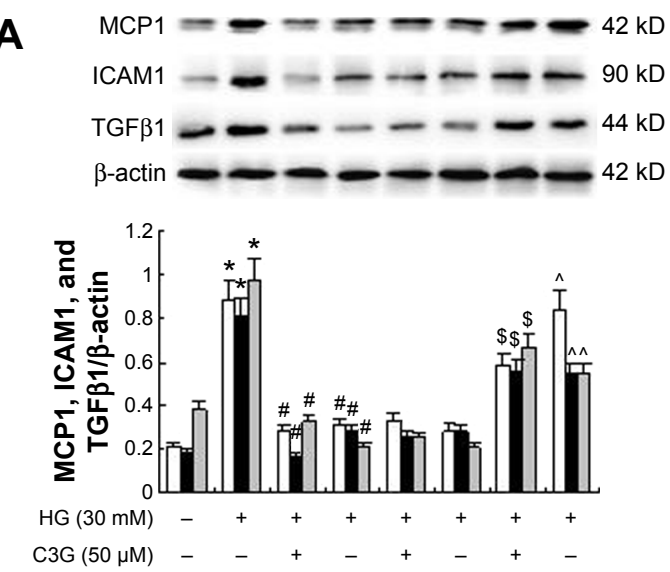

Су $(50 \mu \mathrm{M})$ - $\quad-\quad+\quad+\quad+\quad+$

GW6471 $(25 \mu \mathrm{M})$ - $\quad-\quad-\quad+\quad+-$
B

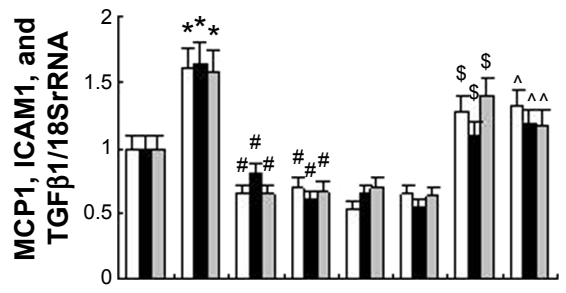

HG (30 mM) C3G $(50 \mu \mathrm{M})$

Cy $(50 \mu \mathrm{M})$

GW6471 $(25 \mu \mathrm{M})$

LXR $\alpha$-shRNA

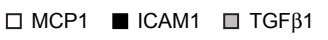

Figure 8 Effects of GW647I and pLV-NRIH3-shRNA plasmid on anthocyanins-mediated reduction of MCPI, ICAMI, and TGF $\beta$ I in HK-2 cells.

Notes: (A) The expression levels of MCPI, ICAMI, and TGF $\beta$ I protein were detected by Western blot. (B) The expression levels of MCPI, ICAMI, and TGF $\beta$ I mRNA were analyzed by $R T-q P C R$. The values presented are the mean \pm SD of three independent experiments. ${ }^{*} P<0.01$ versus control group, ${ }^{\# P}<0.01$ versus $H G$ group. ${ }^{\$} P<0.01$ versus $\mathrm{HG}+\mathrm{C} 3 \mathrm{G}$ group, $\wedge P<0.01$ versus $\mathrm{HG}+\mathrm{Cy}$ group.

Abbreviations: C3G, cyanidin-3-O-B-glucoside chloride; $\mathrm{Cy}$, cyanidin chloride; HG, high-glucose; RT-qPCR, quantitative real-time polymerase chain reaction.

macrophages in a model of acute lung injury. ${ }^{40}$ In addition, PCA inhibited MCP1 expression and attenuated the induction of ICAM1 to ameliorate the diabetic state in diabetic kidneys. ${ }^{41}$ PCA also retarded diabetes-associated renal fibrosis and mesangial inflammation by disturbing TGF $\beta 1$ signaling. ${ }^{8}$ This study revealed that $\mathrm{C} 3 \mathrm{G}$ and $\mathrm{Cy}$ inhibited the production of MCP1, ICAM1, and TGF $\beta 1$ both intracellularly and extracellularly. NFKB is an important transcription factor that plays a critical role in inducing cytokine production; ${ }^{22}$ the anthocyanin-mediated inhibition of HG-induced cytokine production was likely mediated by the NFKB pathway.

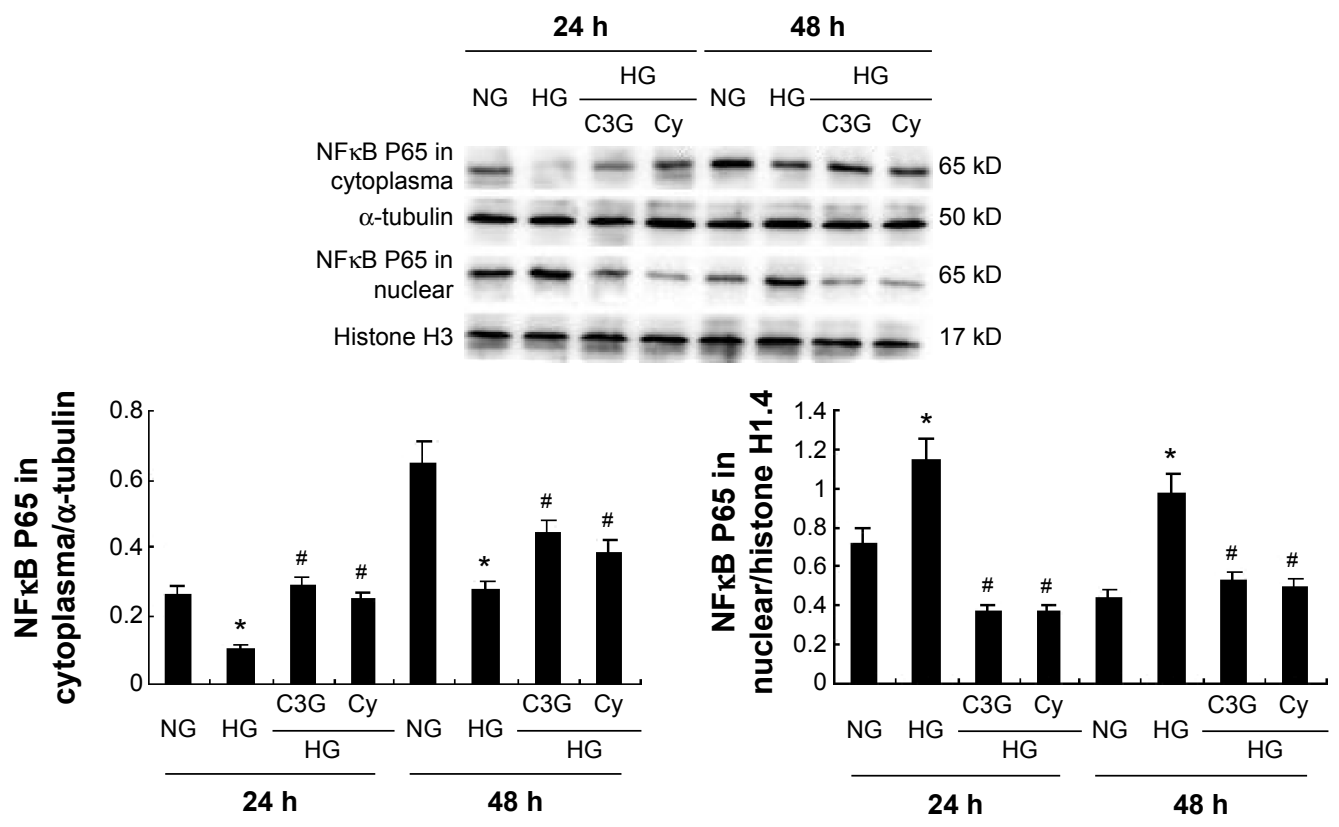

Figure 9 Effects of anthocyanins on HG-induced NFKB expression in HK-2 cells.

Notes: Cells were preincubated with or without C3G and Cy $(50 \mu \mathrm{M})$ for I h and then treated with $30 \mathrm{mM}$ HG for 24 or 48 h. The expression levels of NFKB p65 cytoplasm protein and nuclear protein were detected by Western blot. The values presented are the mean \pm SD of three independent experiments. *P<0.05 versus control group, ${ }^{\#} P<0.05$ versus $\mathrm{HG}$ group.

Abbreviations: C3G, cyanidin-3-O-B-glucoside chloride; Cy, cyanidin chloride; h, hour/s; HG, high-glucose; NG, normal glucose. 
A
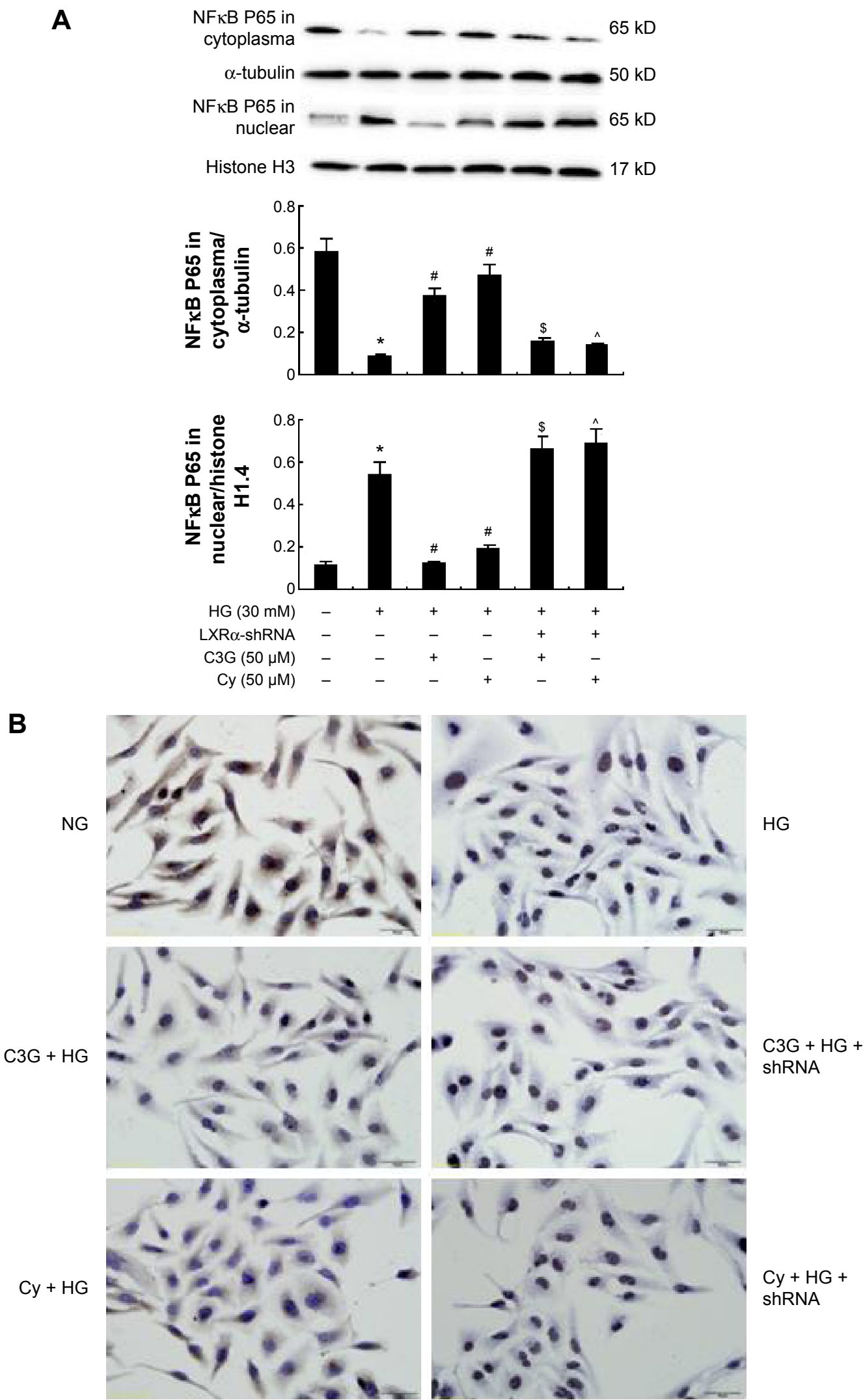

Figure 10 Knockdown of $L X R \alpha$ abrogated the anthocyanins-induced NFKB gene expression in HK-2 cells.

Notes: Cells were transfected with pLV-NRIH3-shRNA plasmid or scrambled control shRNA plasmid for $24 \mathrm{~h}$ and then treated with HG (30 mM) in the presence or absence of C3G and Cy $(50 \mu \mathrm{M})$ for $48 \mathrm{~h}$, respectively. (A) The expression levels of NFkB cytoplasm protein and nuclear protein were detected by Western blot. (B) Nuclear translocation of $N F \kappa B$ p 65 was investigated by immunocytochemistry staining. The values presented are the mean $\pm S D$ of three independent experiments. $* P<0.0 \mathrm{I}$ versus control group, ${ }^{\sharp P}<0.01$ versus $H G$ group. ${ }^{\$} P<0.01$ versus $H G+C 3 G$ group, $\wedge$ P $<0.01$ versus $H G+C y$ group.

Abbreviations: C3G, cyanidin-3-O- $\beta$-glucoside chloride; Cy, cyanidin chloride; h, hour/s; HG, high-glucose; NG, normal glucose. 
Nuclear LXR, and particularly $L X R \alpha$, is an extensively studied and validated gene whose primary function is to maintain cellular cholesterol homeostasis. ${ }^{18,19}$ LXR $\alpha$ regulates intracellular cholesterol levels by mediating the expression of its target gene $A B C A 1$ by binding to an LXR element in the $A B C A 1$ promoter. ${ }^{42}$ In addition to $\mathrm{LXR} \alpha$, the nuclear receptor superfamily member PPAR $\alpha$ plays a critical role in lipid metabolism and regulates the expression of ABCA1. ${ }^{18,19}$ The activation of PPAR $\alpha$ reduces triglyceride, total cholesterol, and LDL levels markedly, and consequently elevates HDL levels. ${ }^{43}$ Moreover, previous studies demonstrated that crosstalk occurs between PPAR $\alpha$ and LXR $\alpha$ during the regulation of cholesterol efflux and that PPAR $\alpha$ induces LXR $\alpha$ expression directly via a response element upstream of the LXR $\alpha$ promoter region. This leads to the induction of ABCA1, followed by a transcriptional cascade that regulates cholesterol removal from macrophages. ${ }^{18,19}$ In addition, PPAR $\alpha$ agonists induce ABCA1 expression and cholesterol efflux in macrophages in an LXR $\alpha$-dependent manner. ${ }^{22,23}$

To investigate the molecular mechanisms by which $\mathrm{C} 3 \mathrm{G}$ and $\mathrm{Cy}$ increased intracellular cholesterol efflux and ABCA1 expression in HK-2 cells, we measured their effects on PPAR $\alpha$ and LXR $\alpha$ activation in the presence and absence of GW6471, a PPAR $\alpha$ inhibitor, and pLVNR1H3-shRNA, an LXR $\alpha$ silencing plasmid. Data revealed that $\mathrm{C} 3 \mathrm{G}$ and $\mathrm{Cy}$ increased PPAR $\alpha$ and LXR $\alpha$ expression. In addition, GW6471 and LXR $\alpha$ shRNA abolished the anthocyanin-mediated increase in cholesterol efflux and ABCA1 expression. Moreover, GW6471 also attenuated anthocyanin-mediated LXR $\alpha$ expression significantly. In contrast, LXR $\alpha$ shRNA did not affect anthocyanin-induced PPAR $\alpha$ expression. Therefore, these combined findings illustrate a complex pathway involving PPAR $\alpha, L X R \alpha$, and ABCA1 that participates in the anthocyanin-mediated increase in cholesterol efflux from HK-2 cells.

Accumulating evidence suggests that PPAR $\alpha$ and LXR $\alpha$ also play an anti-inflammatory role in many inflammatory and metabolic diseases. ${ }^{22,35}$ Our previous experiments demonstrated that anthocyanin inhibited the production of proinflammatory cytokines. Therefore, we detected the effects of GW6471 and pLV-NR1H3-shRNA plasmid on the anthocyanin-mediated decrease in the proinflammatory cytokines MCP1, ICAM1, and TGF $\beta 1$ to further confirm whether PPAR $\alpha$ and LXR $\alpha$ are involved in the anti-inflammatory effects of anthocyanins in HK-2 cells. Silencing LXR $\alpha$ using pLV-NR1H3-shRNA reversed the effects of C3G and Cy on HG-induced MCP1, ICAM1, and TGF $\beta 1$ expression. However, the PPAR $\alpha$ antagonist GW6471 did not have the same effect; therefore, we conclude that $\mathrm{C} 3 \mathrm{G}$ and Cy reduce HG-induced MCP1, ICAM1, and TGF $\beta 1$ expression partly by activating LXR $\alpha$, but not PPAR $\alpha$, in HK-2 cells.

However, additional results showed that the anthocyanininduced inhibition of HG-induced cytokine production was likely mediated by the NFKB pathway. To further confirm the interrelationship between LXR $\alpha$ and NF $\kappa B$ in anthocyanin-mediated decreased cytokine expression, we assessed NFKB activation when LXR $\alpha$ was silenced using pLV-NR1H3-shRNA. These results demonstrated that C3G and $\mathrm{Cy}$ inhibited HG-induced NFאB nuclear translocation markedly, and that this effect was largely abolished when LXR $\alpha$ was silenced using pLV-NR1H3-shRNA. This result is consistent with previous studies reporting that the inhibition of inflammatory gene expression using LXR agonists involves antagonizing NFKB signaling. ${ }^{44,45}$ Taken together, these results suggest that the anti-inflammatory effects of the anthocyanins $\mathrm{C} 3 \mathrm{G}$ and $\mathrm{Cy}$ in $\mathrm{HK}-2$ cells are partly mediated by inhibiting the LXR $\alpha$-stimulated nuclear translocation of $\mathrm{NF \kappa B}$, which further decreases the levels of the proinflammatory cytokines MCP1, ICAM1, and TGF $\beta 1$.

In conclusion, this study demonstrated that anthocyanins modulate cholesterol metabolism and the inflammatory response in HG-stimulated HK-2 cells, suggesting that anthocyanins might have novel therapeutic effects in DN. In addition, $\mathrm{C} 3 \mathrm{G}$ and $\mathrm{Cy}$ had similar antihyperlipidemic and anti-inflammatory properties. Therefore, we hypothesize that the antihyperlipidemic and anti-inflammatory activities are due to their aglycone moiety. However, more work is needed to clarify the structure-function relationship and the effects of anthocyanins.

\section{Acknowledgment}

This study was supported by the National Natural Science Foundation of the People's Republic of China (numbers 81270804 and 81370825) and the Hebei Science and Technology Department Program (12966118D).

\section{Disclosure}

All authors report no conflicts of interest in this work.

\section{References}

1. Kelly KJ, Dominguez JH. Rapid progression of diabetic nephropathy is linked to inflammation and episodes of acute renal failure. Am J Nephrol. 2010;32:469-475.

2. Abdel-Rahman EM, Saadulla L, Reeves WB, Awad AS. Therapeutic modalities in diabetic nephropathy: standard and emerging approaches. J Gen Intern Med. 2012;27:458-468.

3. Herman-Edelstein M, Scherzer P, Tobar A, Levi M, Gafter U. Altered renal lipid metabolism and renal lipid accumulation in human diabetic nephropathy. J Lipid Res. 2014;55:561-572. 
4. Zhang MH, Feng L, Zhu MM, et al. The anti-inflammation effect of Moutan Cortex on advanced glycation end products-induced rat mesangial cells dysfunction and High-glucose-fat diet and streptozotocin-induced diabetic nephropathy rats. J Ethnopharmacol. 2014;151:591-600.

5. Kuhad A, Sachdeva AK, Chopra K. Attenuation of renoinflammatory cascade in experimental model of diabetic nephropathy by sesamol. J Agric Food Chem. 2009;57:6123-6128.

6. Tesch GH. MCP-1/CCL2: a new diagnostic marker and therapeutic target for progressive renal injury in diabetic nephropathy. Am J Physiol Renal Physiol. 2008;294:F697-F701.

7. Hills CE, Al-Rasheed N, Al-Rasheed N, Willars GB, Brunskill NJ. $\mathrm{C}$-peptide reverses TGF-betal-induced changes in renal proximal tubular cells: implications for treatment of diabetic nephropathy. Am J Physiol Renal Physiol. 2009;296:F614-F621.

8. Li J, Lim SS, Lee JY, et al. Purple corn anthocyanins dampened high-glucose-induced mesangial fibrosis and inflammation: possible renoprotective role in diabetic nephropathy. J Nutr Biochem. 2012;23:320-331.

9. Korrapati MC, Howell LH, Shaner BE, Megyesi JK, Siskind LJ, Schnellmann RG. Suramin: a potential therapy for diabetic nephropathy. PLoS One. 2013;8:e73655.

10. Soetikno V, Sari FR, Veeraveedu PT, et al. Curcumin ameliorates macrophage infiltration by inhibiting NF- $\mathrm{KB}$ activation and proinflammatory cytokines in streptozotocin induced-diabetic nephropathy. Nutr Metab (Lond). 2011;8:35.

11. Mezzano S, Aros C, Droguett A, et al. NF-kappaB activation and overexpression of regulated genes in human diabetic nephropathy. Nephrol Dial Transplant. 2004;19:2505-2512.

12. Tang SC, Leung JC, Chan LY, Tsang AW, Lai KN. Activation of tubular epithelial cells in diabetic nephropathy and the role of the peroxisome proliferator-activated receptor-gamma agonist. J Am Soc Nephrol. 2006;17:1633-1643.

13. Xie X, Peng J, Chang X, et al. Activation of RhoA/ROCK regulates NF- $\kappa \mathrm{B}$ signaling pathway in experimental diabetic nephropathy. Mol Cell Endocrinol. 2013;369:86-97.

14. Ruan XZ, Moorhead JF, Fernando R, Wheeler DC, Powis SH, Varghese Z. PPAR agonists protect mesangial cells from interleukin 1beta-induced intracellular lipid accumulation by activating the ABCA1 cholesterol efflux pathway. J Am Soc Nephron. 2003;14:593-600.

15. Merscher-Gomez S, Guzman J, Pedigo CE, et al. Cyclodextrin protects podocytes in diabetic kidney disease. Diabetes. 2013;62:3817-3827.

16. Tang C, Kanter JE, Bornfeldt KE, Leboeuf RC, Oram JF. Diabetes reduces the cholesterol exporter ABCA1 in mouse macrophages and kidneys. J Lipid Res. 2010;51:1719-1728.

17. Zager RA, Johnson AC, Hanson SY, Shah VO. Acute tubular injury causes dysregulation of cellular cholesterol transport proteins. Am J Pathol. 2003;163:313-320.

18. Schmitz G, Langmann T. Transcriptional regulatory networks in lipid metabolism control ABCA1 expression. Biochim Biophys Acta. 2005; 1735:1-19.

19. Nakaya K, Tohyama J, Naik SU, et al. Peroxisome proliferator-activated receptor- $\alpha$ activation promotes macrophage reverse cholesterol transport through a liver X receptor-dependent pathway. Arterioscler Thromb Vasc Biol. 2011;31:1276-1282.

20. Proctor G, Jiang T, Iwahashi M, Wang Z, Li J, Levi M. Regulation of renal fatty acid and cholesterol metabolism, inflammation, and fibrosis in Akita and OVE26 mice with type 1 diabetes. Diabetes. 2006;55:2502-2509.

21. Park CW, Kim HW, Ko SH, et al. Accelerated diabetic nephropathy in mice lacking the peroxisome proliferator-activated receptor alpha. Diabetes. 2006;55:885-893.

22. Johnston TP, Waxman DJ. The induction of atherogenic dyslipidaemia in poloxamer 407-treated mice is not mediated through PPARalpha. J Pharm Pharmacol. 2008;60:753-759.

23. Balakumar P, Kadian S, Mahadevan N. Are PPAR alpha agonists a rational therapeutic strategy for preventing abnormalities of the diabetic kidney? Pharmacol Res. 2012;65:430-436.

24. Kouroumichakis I, Papanas N, Zarogoulidis P, Liakopoulos V, Maltezos E, Mikhailidis DP. Fibrates: therapeutic potential for diabetic nephropathy? Eur J Intern Med. 2012;23:309-316.
25. Zhang-Gandhi CX, Drew PD. Liver X receptor and retinoid X receptor agonists inhibit inflammatory responses of microglia and astrocytes. J Neuroimmunol. 2007;183:50-59.

26. Wang D, Liu M, Wang Y, et al. Synthetic LXR agonist T0901317 attenuates lipopolysaccharide-induced acute lung injury in rats. Int Immunopharmacol. 2011;11:2098-2103.

27. Xing Y, Fan X, Ying D. Liver X receptor agonist treatment promotes the migration of granule neurons during cerebellar development. J Neurochem. 2010;115:1486-1494.

28. Punithavathi VR, Stanely Mainzen Prince P, Kumar MR, Selvakumari CJ. Protective effects of gallic acid on hepatic lipid peroxide metabolism, glycoprotein components and lipids in streptozotocin-induced type II diabetic Wistar rats. J Biochem Mol Toxicol. 2011;25:68-76.

29. Takikawa M, Inoue S, Horio F, Tsuda T. Dietary anthocyanin-rich bilberry extract ameliorates hyperglycemia and insulin sensitivity via activation of AMP-activated protein kinase in diabetic mice. J Nutr. 2010;140:527-533.

30. Wu T, Tang Q, Gao Z, et al. Blueberry and mulberry juice prevent obesity development in C57BL/6 mice. PLoS One. 2013;8:e77585.

31. Zern TL, West KL, Fernandez ML. Grape polyphenols decrease plasma triglycerides and cholesterol accumulation in the aorta of ovariectomized guinea pigs. J Nutr. 2003;133:2268-2272.

32. Galvano F, La Fauci L, Lazzarino G, et al. Cyanidins: metabolism and biological properties. J Nutr Biochem. 2004;15:2-11.

33. Hou DX, Yanagita T, Uto T, Masuzaki S, Fujii M. Anthocyanidins inhibit cyclooxygenase-2 expression in LPS-evoked macrophages: structure-activity relationship and molecular mechanisms involved. Biochem Pharmacol. 2005;70:417-425.

34. Sun CD, Zhang B, Zhang JK, et al. Cyanidin-3-glucoside-rich extract from Chinese bayberry fruit protects pancreatic $\beta$ cells and ameliorates hyperglycemia in streptozotocin-induced diabetic mice. J Med Food. 2012;15:288-298

35. Wang Q, Xia M, Liu C, et al. Cyanidin-3-O-beta-glucoside inhibits iNOS and COX-2 expression by inducing liver $\mathrm{X}$ receptor alpha activation in THP-1 macrophages. Life Sci. 2008;83:176-184.

36. Speciale A, Canali R, Chirafisi J, et al. Cyanidin-3-O-glucoside protection against TNF- $\alpha$-induced endothelial dysfunction: involvement of nuclear factor-кB signaling. J Agric Food Chem. 2010;58:12048-12054.

37. Tufro A. Cholesterol accumulation in podocytes: a potential novel targetable pathway in diabetic nephropathy. Diabetes. 2013;11: 3661-3662.

38. Sasaki R, Nishimura N, Hoshino H. Cyanidin 3-glucoside ameliorates hyperglycemia and insulin sensitivity due to downregulation of retinol binding protein 4 expression in diabetic mice. Biochem Pharmacol. 2007;74:1619-1627.

39. Guo H, Ling W, Wang Q, et al. Effect of anthocyanin-rich extract from black rice (Oryza sativa L. indica) on hyperlipidemia and insulin resistance in fructose-fed rats. Plant Foods Hum Nutr. 2007;62:1-6.

40. Fu Y, Zhou E, Wei Z, et al. Cyanidin-3-O- $\beta$-glucoside ameliorates lipopolysaccharide-induced acute lung injury by reducing TLR4 recruitment into lipid rafts. Biochem Pharmacol. 2014;90:126-134.

41. Kang MK, Li J, Kim JL, et al. Purple corn anthocyanins inhibit diabetesassociated glomerular monocyte activation and macrophage infiltration. Am J Physiol Renal Physiol. 2012;303:F1060-F1069.

42. Venkateswaran A, Laffitte BA, Joseph SB. Control of cellular cholesterol efflux by the nuclear oxysterol receptor LXR alpha. Proc Natl Acad Sci U S A. 2000;97:12097-12102.

43. Chinetti G, Fruchart JC, Staels B. Transcriptional regulation of macrophage cholesterol trafficking by PPARalpha and LXR. Biochem Soc Trans. 2006;34:1128-1131.

44. Crisafulli C, Di Paola R, Mazzon E, et al. Liver X receptor agonist treatment reduced splanchnic ischemia and reperfusion injury. J Leukoc Biol. 2010;87:309-321.

45. Laragione T, Gulko PS. Liver X receptor regulates rheumatoid arthritis fibroblast-like synoviocyte invasiveness, matrix metalloproteinase 2 activation, interleukin-6 and CXCL10. Mol Med. 2012;18:1009-1017. 


\section{Publish your work in this journal}

Drug Design, Development and Therapy is an international, peerreviewed open-access journal that spans the spectrum of drug design and development through to clinical applications. Clinical outcomes, patient safety, and programs for the development and effective, safe, and sustained use of medicines are a feature of the journal, which has also been accepted for indexing on PubMed Central. The manuscript management system is completely online and includes a very quick and fair peer-review system, which is all easy to use. Visit http://www.dovepress.com/testimonials.php to read real quotes from published authors.

Submit your manuscript here: http://www.dovepress.com/drug-design-development-and-therapy-journal 